URL www.una.ac.cr/mhsalud

\title{
Editorial
}

\section{¡Alerta roja para niñas, niñas y jóvenes! ¡A ejercitarse por su salud!}

\author{
Inés Revuelta Sánchez, M.B.A. \\ Académica \\ Facultad de Ciencias de la Salud, Universidad Nacional de Costa \\ Rica. \\ Escuela de Ciencias del Movimiento Humano y Calidad de Vida. \\ inesrevuelta@gmail.com
}

Para nadie es un secreto que las niñas y los niños que antes jugaban en los parques, brincaban y saltaban en las aceras y corrían en las plazas se están desapareciendo. ¡Horror! No se desaparecen por motivo de secuestro ni otras causas delictivas sino porque las presiones de la vida moderna, hacen que cada vez sea más difícil para ellos disfrutar del ejercicio y la actividad física en ambientes naturales tales como parques, plazas y barrios residenciales....

Aunque se ha pasado de los parques a los "plays", de las plazas a las salas de fiestas bajo techo y de los barrios a los condominios, estas posibilidades no constituyen una realidad para todas nuestras niñas y niños. Además, en el caso de los que sí disfrutan de estas posibilidades, muchos prefieren realizar otras actividades que son consecuencia del desarrollo tecnológico que pareciera ser parte del "signo de los tiempos" y que en su gran mayoría, proponen un estilo de vida cada vez más sedentario.

Estos datos están directamente relacionados con la ingesta y consumo de alimentos en estrecha relación con el gasto de energía. Es una cuestión de lógica: si un niño o joven consume alimentos y no se ejercita, brinca, corre, camina, trota, salta o sea, se mueve, entonces los almacena... y si los almacena, tendrá sobrepeso y probablemente obesidad.

Lo anterior está "pasando la factura" en la población infantil a nivel de índices de salud, ya que la obesidad y el sobrepeso se han convertido en uno de los problemas de salud pública más importantes del SXXI. La Organización Mundial de la Salud (OMS) reporta que en el 2010, hay 42 millones de niñas y niños con sobrepeso en el mundo y que estos números se elevan para el 2013. 
URL www.una.ac.cr/mhsalud

La prevalencia del sobrepeso y la obesidad en todos los grupos de edad en niños y jóvenes se ha incrementado durante la última década, pero estos números van en aumento en particular en los escolares y adolescentes, grupos en los que se ha duplicado y triplicado respectivamente. Los datos anteriores constituyen una estadística mundial que está afectando a la población mundial en forma cada vez más alarmante, en particular a nivel de los países de bajos y medianos ingresos y sobretodo en las áreas de población urbanas. Es así como se habla de la "doble carga" a nivel de morbilidad, en la cual la población infantil se ve sometida a problemas relacionados con enfermedades infecciosas así como con otros problemas asociados con la nutrición, lo cual es por sí misma una carga pesada. Y si a esto se añade el hecho de que los niños y jóvenes también se ven enfrentados a un rápido aumento de los factores de riesgo de enfermedades crónicas no transmisibles, ¡carga por partida doble!

Esta doble carga es la consecuencia de la mezcla que se genera como producto de varios factores en la historia de vida de las niñas y los niños y que básicamente está relacionada con la nutrición inadecuada en alguna etapa de la infancia así como con la falta de actividad física a medida que el niño va creciendo.

¡Pero la historia no para ahí! Resulta que estos estilos de vida poco saludables durante la infancia, tienen un gran impacto también a largo plazo. La obesidad y el sobrepeso infantil se asocian a una mayor probabilidad de muerte y discapacidad prematuras en la edad adulta, ya que aquellas niñas y niños que son obesos en la infancia, probablemente también lo serán como jóvenes y en la edad adulta por lo cual, podrían padecer enfermedades crónicas no transmisibles a edades cada vez más tempranas.

La ecuación se complica un poco más (¡cómo si no fuera poco!), cuando se entiende que para un niño o niña, el riesgo y las consecuencias derivadas de tener obesidad y sobrepeso están directamente relacionados con la edad de inicio y el tiempo en que se tienen estos y que, a partir de ahí, se generan una serie de problemas que aparecerán con mayor probabilidad en la edad adulta, entre los cuales, la OMS indica la siguiente lista:

- las enfermedades cardiovasculares (principalmente las cardiopatías y los accidentes vasculares cerebrales);

- la diabetes;

- los trastornos del aparato locomotor, en particular la artrosis, y

- ciertos tipos de cáncer (de endometrio, mama y colon)

Es un asunto de simple matemática; números que impactan otros números. Números que disminuyen por un lado causando que otros números se eleven: nuestros niños y 
URL www.una.ac.cr/mhsalud

niñas desaparecen no sólo de los parques, plazas y barrios sino que pasan a engrosan los índices de población enferma.

Si se tratara de sólo números, quizás no trascendería en mayor medida, pero se trata de niños, niñas y jóvenes de hoy...nuestros hijos, nietos, sobrinos... nuestros adultos del mañana que a la vez son la generación que educará a la que sigue con sus mismos hábitos, buenos o malos. ¡Es una cadena que debemos romper!

A pesar de lo anterior, se ha observado que en aquellos países el mundo en los que se están promoviendo cambios en los estilos de vida, se está produciendo un cambio en la incidencia del sobrepeso y la obesidad; esta situación se ha observado como producto de los cambios en los estilos de vida, fundamentalmente con la disminución en la ingesta de energía y aumento en la cantidad de actividad diaria. Vuelve a ser un asunto de números: bajar la ingesta y aumentar el ejercicio y la actividad física.

Las organizaciones que promueven el ejercicio están contemplando aumentar las cantidades de actividad física recomendadas en sus Guías de Actividad Física. En particular, para los niños y niñas se está considerando recomendar 80 minutos diarios en contraposición con los 60 minutos diarios de actividad física durante 7 días a la semana que se recomiendan en la actualidad para la población infantil.

Independientemente de la cantidad, hay que recordar que algo es mejor que nada y que la consigna es ejercitarse, moverse ....jahora!

Es este un llamado a que pongamos a nuestras niñas y niños en movimiento sobretodo ahora que las vacaciones se aproximan y que la población escolar y juvenil sale a las calles, plazas y barrios...y si no hay calles, plazas y barrios, busquemos opciones en las que impere el movimiento, el ejercicio y la actividad física.

Hablemos con los niños, niñas y jóvenes haciendo conciencia sobre la verdadera situación, conversemos sobre sus opciones y enfoquemos la importancia que tienen el ejercicio y la actividad física como un asunto de salud y no sólo de estética. Al final de cuentas es una verdadera alerta roja ya que es, ¡ es un asunto de vida!

Inés Revuelta Sánchez, M.B.A.

Académica de la Escuela de Ciencias del Movimiento Humano y Calidad de Vida de la Universidad Nacional y gestora del Programa Bandera Activa, por la promoción del ejercicio en poblaciones infantiles y juveniles del Programa Ejercicio es Medicina, Costa Rica 
Revista en Ciencias del Movimiento Humano y Salud

URL www.una.ac.cr/mhsalud

Revista MHSalud® (ISSN: 1659-097X) Vol. 10. No. 2. Agosto-Diciembre, 2013 https://doi.org/10.15359/mhs.10-2.1 